\title{
Defending medical negligence claims: a surgeon's guide (part II)
}

\author{
Avanti Perera \\ Attorney General's Department of Sri Lanka.
}

Continued from Previous Issue....

\section{Avenues to Defend}

7) Disclosure and consent

The defence of disclosure and consent is particularly significant to surgical practice, because it is at the point of treatment by surgery that risk disclosure by the surgeon and consent by the patient becomes relevant. This is because, unlike previous stages of the doctor-patient relationship, such as the stage of consultation or diagnosis, bodily invasion of a serious nature occurs during surgery.

Invasion occurs to a much lesser extent during clinical examination or treatment by prescribing medication. For reasons of brevity, this part of the discussion will not include the historical or moral/ethical/fiduciary dimensions of disclosure and consent relating to medical treatment nor the issue of capacity to consent. It will be confined to the manner in which the law treats disclosure as a requirement and, consequently, consent as a defence in relation to medical negligence.

Although the famous Bolam case too concerned the doctor's failure to warn the patient of the risks of electroconvulsive therapy, it is in Sidaway v. Board of Governors of the Bethlem Royal Hospital and Maudsley Hospital [1], that a detailed judicial analysis of the duty of disclosure and patient consent is provided by a UK court. In this case, the claimant complained that the neurosurgeon had not warned her of a 1$2 \%$ risk of paraplegia which was associated with the surgical procedure of cervical cord decompression - which warning would have caused her to forego the surgery - and that the surgery had resulted in damage to the spinal cord, leaving her with a serious disability. While all of the judges were in agreement that doctors owe a duty of care to disclose information, no uniform approach as to the standard of this duty of care is found in the House of Lords judgment.

Correspondence: Avanti Perera D.Phil (Oxon) LL.M (Hons)

(Cantab) BA (English) (Hons) (Colombo)

Senior State Counsel, Attorney General's Department of Sri Lanka

E-mail: perera.avanti@gmail.com

Received: 18-12-2016 Accepted: 26-02-2017

DOI: http://doi.org/10.4038/sljs.v35i1.8349

The Sri Lanka Journal of Surgery 2017; 35(1): 19-24
Lord Diplock applied the Bolam standard, thus holding that the level of disclosure should be in conformity with responsible medical practice, Lord Scarman referred to cases from Canada and the USA on informed consent and a patient's basic human right to make his own medical decisions and Lords Bridge, Keith and Templeman attempted to strike a balance between the two positions. However, the unanimous decision was that there had not been any negligence by the defendant's failure to disclose the risk.

Yet, the current trend across jurisdictions seems to be veering towards the application of the prudent patient test (what a reasonable person in the patient's position would want to know) rather than the reasonable doctor test (what a doctor ought to disclose to a patient, according to accepted medical practice). For example, Lord Diplock's approach based on the latter test was not followed in subsequent decisions in UK courts and has been expressly rejected by courts in some Commonwealth jurisdictions, as well as South Africa.

In Pearce v. United Bristol Healthcare NHS Trust [2], the consultant had not warned a pregnant woman of the $0.1-0.2 \%$ risk of still-birth associated with natural birth, despite the fact that she was two weeks overdue and had begged for induced labour or a caesarean, and the baby died in utero a few days later. Lord Woolf came to a finding of negligence, on the basis that the risk disclosure would have affected the judgment of a reasonable patient. This decision was followed in the cases of Chester v. Afshar [3] and Birch v. UCL Hospital Foundation Trust [4]. In the Chester case, the patient having suffered a motor and sensory disturbance in her body, consequent to spinal surgery, the same surgeon decided that another operation was necessary. But he failed to disclose a small risk of cauda equana which results in severe disability and that risk unfortunately materialised after the second surgery. Lord Steyn held that there was negligence by the defendant surgeon:

A surgeon owes a legal duty to a patient to warn him or her in general terms of possible serious risks involved in the procedure. The only qualification is that there may be wholly exceptional cases where objectively in the best interest of the patient the surgeon may be excused from giving a warning. This is, however, irrelevant to the 
present case. In modern law medical paternalism no longer rules and a patient has a prima facie right to be informed by a surgeon of a small, but well established, risk of serious injury as a result of surgery.

In the Australian case of Rogers v. Whitaker [5], the Bolam test was discarded insofar as the field of non-disclosure of risk and the provision of advice and information are concerned and court held that "while evidence of acceptable medical practice is a useful guide for the courts, it is for the court to adjudicate on what is the appropriate standard of care after giving weight to 'the paramount consideration that a person is entitled to make his own decisions about his life [5]." Likewise, in the Canadian cases of Reibl v. Hughes [6] and Hopp v. Lepp [7], patient autonomy was central to the test applied. In the Reibl case, the claimant testified that, had he known about the risk involved, he would have postponed the surgery until his lifetime retirement pension started. In holding the surgeon liable for negligence, court also took into consideration the fact that surgeon should have taken special care to ensure that he was understood, considering that the patient's difficulty with the English language. In a later case, Haughian v. Paine [8], the neurosurgeon's failure to inform of the risk of paralysis associated with the recommended surgery and failure to inform of the alternatives of no treatment and conservative management were held to be negligent.

Furthermore, "in South Africa, informed consent is routinely endorsed in the health care field and confirms that it is a valid defence to medical malpractice [9]." The decision in Castell v De Greef [10] is particularly significant because court viewed informed consent upon a right-based approach, by accepting patients' autonomy as a fundamental right in South Africa against medical supremacy. Here, the specialist plastic surgeon had not warned the patient of the material risks and complications which were associated with the surgical operation known as a subcutaneous mastectomy. Because of necrosis of skin underlying tissues, it has a high risk of complications. Necrosis followed after the initial operation and the patient had to undergo several further surgical procedures, causing her to suffer physically, mentally and financially. The surgeon was found negligent for failure to disclose the risk.

It must also be stressed that the legal requirement of disclosure not only includes a surgeon's duty to inform the patient of potential risks of the proposed surgery, but also the duty to inform patients of errors caused during surgery and which now pose fresh risks. In such cases, the surgical error itself may not have been a negligent act, but the failure to inform the patient of that error can attract legal liability. This is because the injury caused by the non-negligent error will nonetheless present risks associated with the patient's future health and, without that knowledge, the patient would be exposed to danger. Since the failure to disclose surgical errors has generally been treated as a breach of fiduciary duty rather than a breach of the duty of (medical) care and it is the latter which is relevant to medical negligence litigation, this paper will not elaborate on the subject any further. However, it is important for surgeons to be mindful that they owe to their patient a duty of candour, as much as a duty of care [11].

One way to formulate a defence where medical negligence claims are based on lack of informed consent is to comply with and rely on available clinical guidelines on the subject. In the UK, the General Medical Council has stipulated guidelines on consent, based on a subjective patient-specific standard of information disclosure [12]. Another defence associated with the defence of obtaining informed consent is that of assumption of risk (volenti non fit injuria). In such cases, a patient elects/rejects treatment, assuming the risk which has been adequately disclosed to him, and the question is whether a doctor could still be liable if that risk materializes. Examples are found often where patients' religious beliefs influence their healthcare decisions. For instance, in the Nigerian case of Okonkwo v. Medical and Dental Practitioners' Disciplinary Tribunal [13], the anaemic patient was a Jehovah's Witness and refused a blood transfusion although no alternative treatment was available, a decision which eventually led to her untimely death. The mother of the patient complained to the Disciplinary Tribunal which found the defendant doctor negligent. However, in appeal, the court reversed that finding, on the basis that the doctor had adequately discharged his duty of disclosure and the patient had assumed the risk.

Before winding up the discussion on the defence of consent, it is also important to realize that if consent has not been obtained, informed or otherwise, surgeons would be causing trespass to the person and thus liable for battery under the law of tort or the offence of assault under criminal law. In Chatterton v. Gerson [14], the patient who was suffering from chronic and unendurable pain in a post-operative scar and sent to a pain clinic for treatment had consented to the surgical procedure of blocking a sensory nerve which ultimately led to her losing sensation in one leg. Therefore, although she claimed that the failure to inform her of the procedure's implications, such as temporary loss of muscle power, amounted to no consent at all, court was reluctant to come to a finding of battery on this basis: "... once the patient is informed in broad terms of the nature of the procedure which is intended, and gives her consent, that consent is real, and the cause of action on which to base a claim for failure to go into risks and implications is negligence, not trespass"[14]. However, the judgment cites an older decision where a charge of battery was successfully maintained in the case of a boy who was admitted to hospital for a tonsillectomy and, due to an administrative error, was circumcised instead. In Wells v. Surrey AHA [15], where a sterilization operation was first suggested to the patient during labour, at a stage when she 
would not have been in a position to appreciate the implications of surgery, and sterilization was thereafter carried out at the same time as a caesarean section, court once again found that inadequate advice about the surgery amounted only to negligence and not battery. Similarly, in the South African case of Lowrense v Oldwage [16], the claim was that the defendant surgeon who performed vascular surgery on the patient had not warned of the risk of claudication and, as a result, there was inadequate consent to surgery, and the operation therefore constituted an assault. In rejecting liability for assault, the Supreme Court of Appeal appears to have accepted the evidence of the defendant's medical expert, that the likelihood of the risk of claudication occurring was $2 \%$ and concluded that the risk to the plaintiff was so negligible that it was not unreasonable for the defendant not to mention it [16].

To conclude the discussion on a defence based on disclosure and consent, it is appropriate to consider the practical problem of establishing before a court of law what information was, in fact, disclosed to the patient prior to a surgery:

Patients are unlikely to have made notes during their encounter with the doctor, and many years later, may not be able to accurately recall what they were told. Doctors' notes seldom record every detail of the conversations they have had with patients, and it is often difficult for doctors to remember exactly what passed between them and an individual patient, particularly if the consultation happened some years ago, the courts will therefore often be faced with two contradictory accounts of the discussions that took place prior to treatment. Evidence of a doctor's usual practice will sometimes be relevant, though in many cases, the judge will simply have to decide who the more credible witness is [17].

Needless to say, a comprehensive consent form is the best evidence of disclosure and consent. However, problems posed by illiteracy, the paternalistic doctor-patient relationship and attitudes, especially, the blind faith that patients in Sri Lanka continue to repose in their doctors call into question whether a signature on a consent form is the "real consent" that would pass the legal test of disclosure and informed consent.

\section{8) Lack of causation}

Research in the USA has revealed that the prevalent types of injuries caused by surgical errors are operative injuries, visceral/nerve injuries, unexpected bleeding, a foreign body left in the patient, failure to relieve, musculoskeletal injuries, wrong site injuries and wrong patient injuries [18]. While most of these injuries demonstrate that the facts speak for themselves (res ipsa loquitur) that the injury could be directly attributed to a surgical error, it may not always be possible to trace the cause of an injury to an act of medical negligence by the surgeon. This is an important element in the construction of a defence on behalf of a surgeon, because it gives him a chance to fight liability in a medical negligence lawsuit, even though he may have been negligent. The Priyani Soyza case provides a classic example; for, although the Supreme Court found the doctor to have been remiss in not having properly maintained the BHT and not ordering a CT scan, it was also of the view that, because the patient was suffering from a terminal illness from which she would have died in any event, there was no causal link between the doctor's negligence and the patient's death [19].

The legal test used to determine causation is the 'but-for' test. In a medical negligence case, the question to be answered is, but for the defendant's negligence would the claimant have suffered the injury? If a patient is injured in the course of a medical event, a doctor would be found liable for medical negligence if there was an error and the injury complained of was caused by that error. Therefore, even if court comes to a finding that a surgical error has occurred, it would be part of the formulation of the surgeon's defence to say that the claimant had not been able to prove that it was that error which caused the injury and offer instead other explanations, i.e. that the injury is a pre-existing injury or that an intervening factor for which the doctor is not responsible broke the chain of causation.

Where there is no question that the injury can be solely attributed to the surgical error and that error alone, there is little or no defence. However, if there is uncertainty in the link between the error and the link, the defendant doctor is on a better wicket to avoid liability. In the Wilsher case, excess of oxygen on two occasions was only one of five possible causes of the patient's blindness and, so, without a definite causal nexus between the excess of oxygen and the injury, the claimant's case failed. In loss of chance cases, the claimant has to prove on a balance of probabilities that the negligence materially contributed to the injury.

Thus, the inability of the claimant to prove that the delayed diagnosis/treatment following a hip injury from a fall was more likely than not to have caused avascular necrosis resulted in his action being dismissed, in the case of Hotson v. East Berkshire AHA [20]. In Gregg v. Scott [21], where the GP had failed to diagnose a lymphoma and refer the patient to a specialist, the claimant could not prove, on a balance of probabilities that his chance of survival had reduced by the misdiagnosis because the prospect of recovery was less than $50 \%$. On the other hand, in Gouldsmith v. Mid Staffordshire General Hospitals NHS Trust [22], the claimant was able to prove that, had she been referred to specialist hospital for the lesions which she was suffering from, it was more likely than not that a specialist would have operated and she could have avoided having her fingers amputated. Therefore, both cases 
applied the 'but-for' test; but, while in the former case, a successful defence could be made out on lack of causation, it was not so in the latter.

It is pertinent to observe that both proving and disproving causation in cases where there is no straightforward link between the negligence act and the injury depend on an assessment of hypothetical situations. It is particularly so in cases where medical negligence is alleged on the ground of failure to obtain informed consent. In a surgical case, if a reasonable patient would have agreed to the proposed surgery even if informed of its risks, then the onus is on the patient to prove that, had he been so informed, he would have declined the surgery. According to the decision in Smith v. Barking, Havering and Brentwood HA [23], if everything points to the fact that a reasonable patent, properly informed, would have assented to the operation, a post-facto assertion by the patient that he would have acted otherwise, is not sufficient unless supported by additional factors. This was followed in SEM v. The Mid Yorkshire Hospitals NHS Trust [24], where it was admitted that the consultant had been negligent in failing to offer the patient an alternative to a hysterectomy, but the patient was unable to prove to the satisfaction of court that she would have opted for a less invasive form of treatment, if given a choice. In contrast, in O'Keefe v. Harvey-Kemble [25], court accepted that the patient would not have had breast augmentation surgery if she had been warned of the risks involved, while in Birch v. University College London Hospital NHS Foundation Trust [26], the judge accepted the patient's evidence that she would have opted for an MRI scan rather than a catheter angiography, had she been properly informed.

However, there have been cases where courts have given divided opinions, demonstrating how difficult it is to prove/disprove a causal connection between an error in the form of non-disclosure of risks and the injury sustained due to a surgery. In the Chester case (discussed earlier in relation to consent), the House of Lords by a 3-2 majority view, found the defendant surgeon liable, even though the negligence was only the failure to warn the patient of a small risk albeit of serious injury and whether the patient's decision to go ahead with the surgery would have been any different, had she known of such risk was not a matter which could be definitively assessed. Here, the patient only said that, had she known of the risk, she would have sought a second opinion, advice on alternatives, taken time to think it over (not agreed to the surgery at the time, but not ruling it out altogether, forever, either).

The decision followed the Australian case of Chapple v Hart [27], where the ENT surgeon who removed a pharyngeal pouch from the patient's oesophagus had not given prior warning of the risk of injury to the laryngeal nerve and consequent risk of partial or total loss of voice. Having suffered damage to the laryngeal nerve due to the surgery, the patient claimed that, had she been warned of the risk, she would have considered the possibility of having the surgery done by a more experienced surgeon at a later time. The judicial observations made in these cases suggest that both decisions were based on a patient's right to know, rather than a deliberate relaxation of the test of causation. Therefore, are surgeons expected to warn patients of every possible risk involved in an operation? Do patients really want to know every such detail? Does it make a difference to a patient's decision to undergo a particular surgery?

In the above context, the final decision in the South African case of Nicola McDonald v Dr Graham Wroe [28] offers a lifeline to surgeons. In this case, the patient claimed that the defendant surgeon had been negligent, because he had failed to offer her the option of a referral to a specialist maxillofacial oral surgeon for the extraction of her wisdom teeth and to inform her of the risk of permanent nerve damage to her left inferior alveolar nerve. Although the original court held that there was a sufficient link between the non-disclosure of the risk of injury and the patient having actually had to suffer that injury, the High Court in appeal had this to say:

"The harm which the plaintiff suffered, is due to a risk which is inherent in the surgical procedure in question and which can ensue without negligence on the part of the practitioner, be it a general practitioner or a specialist, who performs the procedure. The harm which the plaintiff suffered, is harm she might equally probably have suffered in any event if the surgery had been performed by a specialist surgeon. There is, therefore, no direct causal link between the defendant's negligence (in failing to warn the plaintiff of the risk) and occurrence of the harm, unless it is shown that the plaintiff, upon being warned of risk, would not have undergone the procedure at all. That is not the plaintiff's case" [28].

\section{9) Other defences}

There are a few other defences which may be useful in medical negligence litigation. For instance, the defence of contributory negligence can be raised in situations where a patient does not return to see the doctor on a scheduled date, does not adequately inform the doctor of the nature of symptoms or does not follow a treatment plan, etc. While there have been some cases in which this defence has served to reduce the liability of the doctor, there are many cases where it has also failed [29].

Furthermore, statutory limitations can provide a surgeon with a technical defence if a medical negligence lawsuit has been filed out of time. In Sri Lanka, legal action based on a personal injury claim by a private party (which includes medical negligence litigation) should be instituted within two years of the incident [30]. 


\section{Conclusion}

The several factors discussed above demonstrate the avenues available for a surgeon in constructing a defence case in medical negligence litigation. As much as it is good to be aware of these defences in the unfortunate and unpleasant event of having to face such litigation, this paper would be incomplete if the attention of the medical community is not drawn to some pointers on how to avoid litigation altogether. Of course, the first step is to avoid the occurrence of negligence itself. However, this is easier said than done. And it is particularly not for a lawyer as myself to venture into the territory of medical expertise and offer advice on how surgical errors could be prevented, though the common causes of negligence identified in numerous studies certainly help surgeons to learn from mistakes and prevent recurrence.

However, an area on which this paper can provide advice is how medical negligence litigation may be prevented, even if a surgeon has erred and an injury has resulted. As you may recall, not every surgical error reaches a court of law. Many socio-legal variables in Sri Lanka determine the trajectory of the journey from a medical mishap to medical negligence litigation. Research in this country has revealed that medical injuries turn into grievances for a variety of reasons such as the level of healthcare knowledge, access to information, extent of trust in doctors, awareness of rights, demographic traits of injured parties etc. [31]. Surgeons cannot obviously be in control of many of these factors. However, one aspect which does lie within the control of a surgeon is the doctorpatient relationship. Therefore, it would be safe to say that a surgeon in whom a greater level of trust is placed is more likely to be forgiven for his mistake, less likely to be sued for negligence.

Furthermore, not every aggrieved party will desire to make a claim of medical negligence. In this instance, socio-legal variables which affect grievance management - intensity of the injurious experience, nature of the relationship with the healthcare sector, response received from healthcare service providers in the aftermath of an adverse event, influence of third parties and perception of claiming - determine whether an injured party would consider making a claim against the doctor concerned [31].

Once again, a surgeon cannot be responsible for all of these variables, but if his post-incident conduct is dismissive or evasive, an injured party may be more likely to resort to making a claim against him. This is because it has been found that the main goal of making claims of medical negligence, including litigating is a desire to initiate an inquiry into the adverse incident and thereby prevent recurrence [32]. Therefore, it would be useful for surgeons to note that better communication skills with their patients, both before and after treatment, could reduce the probability of medical negligence litigation.
In conclusion, it is reiterated that, whilst everything possible should be done to avoid surgical errors, when such errors do happen, surgeons should be mindful of avenues to prevent medical negligence litigation, as well as the limits of defences available in law if medical negligence lawsuits are in fact instituted.

The author discloses no conflict of interest.

\section{References}

1. Sidaway v. Board of Governors of the Bethlem Royal Hospital and Maudsley Hospital [1985] AC 871

2. Pearce v. United Bristol Healthcare NHS Trust (1998) 48 BMLR $118[\mathrm{CA}]$

3. Chester v. Afshar [2004] UKHL 41

4. Birch v. UCL Hospital Foundation Trust [2008] EWHC 2237 (QB)

5. Rogers v Whitaker (1993)ALJR 47 at 51

6. Reibl v. Hughes [1980] 2 SCR 880

7. Hopp v. Lepp [1980] 2 SCR 196

8. Haughian v. Paine (1987) 37 D.L.R. (4th) 624

9. Liyanage US. Applicability of the defence of informed consent against medical negligence in the scope of a patient's autonomy: A Sri Lankan perspective. Sri Lanka JIL 2008;(20) II; 117

10. Castell v De Greef (1994) 4 SA 408 (C)

11. Perera A. Medical Error and the Duty of Candour. Law College Law Review 2014; 127-140

12. Consent guidance in Good Medical Practice (2013). Available at: http://www.gmc-uk.org/guidance/ethical_guidance/consent_ guidance_index.asp.

13. Okonkwo v. Medical and Dental Practitioners' Disciplinary Tribunal [1999] 9 NWLR (Pt 617) 1, cited in Iyioha, 90-91

14. Chatterton v. Gerson [1981] QB 432

15. Wells v. Surrey AHA The Times, 29 July 1978, cited in Jackson, 175

16. Lowrense v Oldwage [2004] 1 All SA 532 (C)

17. Jackson E. Medical Law: Text, Cases and Materials. 2nd edition. Oxford: Oxford University Press; 2010 (previous article)

18. Rogers SO, Gawande AA, Kwaan M, Puopolo AL, Yoon C, Brennan TA, Studdert DM. Analysis of surgical errors in closed malpractice claims at 4 liability insurers. Surgery 2006; 140: 2533.

19. Prof. Priyani Soyza v. Rienzie Arsecularatne 2001(2) Sri.L.R.293

20. Hotson v. East Berkshire AHA[1987] 1 AC 750

21. Gregg v. Scott [2005] UKHL2

22. Gouldsmith v. Mid Staffordshire General Hospitals NHS Trust [2007] EWCACiv 397

23. Smith v. Barking, Havering and Brentwood HA [1994] 5 Med L.R. 285

24. SEM v. The Mid Yorkshire Hospitals NHS Trust [2006] EWCA Civ 643

25. O'Keefe v. Harvey-Kemble (1999) 45 BMLR 74 (CA)

26. Birch v. University College London Hospital NHS Foundation Trust [2008] EWHC 2237 (QB)

27. Chapple v Hart (1998) 195 CLR 232

28. Nicola McDonald v Dr Graham Wroe (2006) 3 All SA 565 (C) 
29. Yule J. Defences in Medical Negligence: To what extent has Tort Law Reform in Australia limited the Liability of Health Professionals? JALTA 2011;4(1\&2):53-63

30. Prescription Ordinance, No. 22 of 1871 , section 9

31. Perera A. Medical Negligence Claims in Sri Lanka. New Delhi:
Har-Anand Publications; 2016

32. De Silva AP, Athukorala EAJR, De Silva STGR, Sivakumaran S. A descriptive study on the complaints of medical negligence received by the Ministry of Healthcare and Nutrition. Ceylon Medical Journal 2010; 55(1):31 